\title{
pMicrostructure and mechanical properties of carbon nanotubes reinforced aluminum matrix composites synthesized via equal-channel angular pressing
}

\author{
Hassan Zare a, Mohammad Jahedi b,*, Mohammad Reza Toroghinejad a , Mahmoud \\ Meratian $^{\text {a }}$, Marko Knezevic ${ }^{\mathrm{b}}$

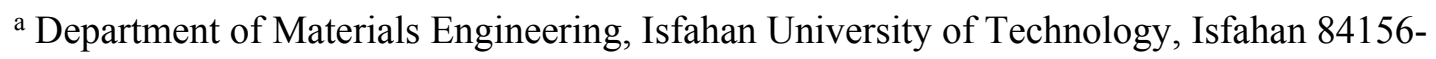 \\ 83111, Iran. \\ ${ }^{\mathrm{b}}$ Department of Mechanical Engineering, University of New Hampshire, Durham, NH \\ 03824, USA.
}

\begin{abstract}
In this work, 2 vol. \% carbon nanotubes (CNTs) reinforced aluminum (Al) matrix composites of superior microstructural homogeneity are successfully synthesized using $\mathrm{Bc}$ equal-channel angular extrusion (ECAP) route. The key step in arriving at high level of homogeneous distribution of CNTs within Al was preparation of the powder using simultaneous attrition milling and ultra-sonication processes. Microstructure as revealed by electron microscopy and absence of Vickers hardness gradients across the material demonstrate that the material reached the homogeneous state in terms of CNT distribution, porosity distribution, and grain structure after eight ECAP passes. To facilitate comparison of microstructure and hardness, samples of Al were processed under the same ECAP conditions. Significantly, the composite containing only 2 vol. \% exhibits $20 \%$ increase in hardness relative to the Al samples.
\end{abstract}

Keywords: Metal matrix composites; Powder processing; Severe plastic deformation; Particle distribution; Consolidation

\section{Introduction}

Carbon nanotube (CNT) reinforced metallic matrix composites are being increasingly explored to enhance various properties of the matrix materials such as strength [1-4], conductivity [5], corrosion resistance [6,7], and magnetic properties [8-10]. Critical to the realization of such materials with improved properties is the development of fabrication

\footnotetext{
${ }^{*}$ Corresponding author at: Department of Mechanical Engineering, University of New Hampshire, 33 Academic Way, Kingsbury Hall, W322, Durham, NH 03824, USA.

E-mail address: mohammad.jahedi@unh.edu (M. Jahedi).
} 
techniques providing a homogeneous dispersion of nanotubes in the metallic matrix. As a result of fabrication, these materials are usually nanostructured in terms of not only CNTs distribution but also in terms of grain size distribution, which provides another strengthening mechanism originating from large content of grain boundary area defects and dislocation substructures [1114]. To date, a number of nano-materials have been synthesized to exit in the form of atomic clusters or nano-particles [15-17], nano-crystallines [18-20], nano-rods [21-23], nano-tubes $[24,25]$, and nano-layers [26-28]. These nano-materials are used as a constituent in creating nano-composites. By definition, nano-composites consist of two or more components, where one or more of the constituents have less than $100 \mathrm{~nm}$ in a length scale. Structurally, particles and reinforcing fibers or layers are enhancing the strength in the matrix of the composite. Most generally, nano-composites can be classified based on the matrix material as: the polymer matrix nano-composites $[29,30]$, nano-composites with ceramic matrix [31,32], and metal matrix nano-composites $[3,33]$. This study is focused on the metal matrix nano-composite (MMNC). MMNCs have wide applications in the automotive and aerospace industries due to the lightweight, high strength, and stiffness. Applications include: automotive like disk brakes [34-37], cutting tools such as tungsten carbide cutting tools [38, 39], and aerospace like monofilament silicon carbide fibers in a titanium matrix for jet's landing gear [40-42].

CNT as one of the carbon allotropy has unique properties arising from their symmetric crystal structure. Mechanical properties of CNTs are far beyond the mechanical properties of any matrix material rising an exciting opportunity of using them as a reinforcing material within a given matrix material. Single-walled CNTs possess theoretical Young's modulus of approximately $5 \mathrm{TPa}$. The average Young's modulus of multi-walled CNTs is reported to be around 1.8 TPa and its flexural strength is $14.2 \mathrm{GPa}[43,44]$. Not only mechanical properties but also light weight, high length to diameter ratio, excellent electrical and thermal properties make CNTs be well-suited to be used as reinforcements in a number of materials.

Compared to the other reinforcements like $\mathrm{SiC}, \mathrm{B}_{4} \mathrm{C}$, and $\mathrm{Al}_{2} \mathrm{O}_{3}, \mathrm{CNT}$ s have not been widely used in the metal-reinforced nano-composites mainly due to difficulties in achieving dispersion of the CNTs in the metallic matrix. Additionally, interfacial chemical reaction of CNTs with a metal within the composite is usually weak even at high temperature and pressure, which typically reduces the efficiency of the CNTs reinforcements in nano-composites $[24,25$, $45,46]$. To overcome this issue, researchers have explored several advanced methods to enhance dispersion of CNTs within a metal matrix. For example, Noguchi et al. [47] utilized a nano-scale dispersion method in Al-CNT composites by setting up an elastomer precursor, Cha 
et al. [48] took an action into a molecular level in the copper matrix composites by means of a salt containing $\mathrm{Cu}$ ions, and $\mathrm{Hu}$ et al. [49] suggested an in-situ reduction approach in Au-CNT composites.

Enhanced mechanical and functional properties have been achieved using CNTs reinforced metallic matrix composites synthesized with variable content of CNTs. For example, substantial improvements in fracture toughness, wear resistance, and hardness were obtained with 10-15 vol.\% CNTs in Cu-CNT composites fabricated by hot pressing sintering [50]. A $70 \%$ increase in micro-hardness was reported in Al6061-CNT composites made by plasma spray forming when $10 \mathrm{wt} . \%$ CNTs was added to Al matrix [51] while a 65\% decrease in coefficient of thermal expansion (CTE) was found when 15 vol.\% CNTs were added to the nano-Al matrix [52]. An addition of 4 vol.\% CNTs [53] was observed to yield more grain refinement than non-reinforced copper via high pressure torsion (HPT) process as well as a 1 vol.\% CNTs to the copper matrix to achieve full density after 8 passes of equal channel angular pressing (ECAP) [54]. It has also been observed that at higher CNT (more than 5 vol.\%) [55], loading properties such as yield and tensile strengths tend to degrade. This is due to the inability of most of the processes to homogeneously distribute CNTs or to obtain dense components at high CNT content as well as improper bonding could lead to inefficient load transfer to the CNTs. Optimal content of CNTs in metal matrix composites enhancing the mechanical properties was reviewed in [55-57] and it was found to be the most effective when the content is 2 vol. \%.

Conventional deformation processes such as rolling and extrusion have been utilized extensively in the consolidation of the powders [33, 58]. It was found that improving the consolidation and homogeneity requires very high strains $(>4)$, especially for composites containing fine particles. The processes of severe plastic deformation (SPD) have attracted much attention due to their ability to impart large plastic strains and thus substantially improve the homogeneity of particle distribution. While SPD processes such as equal channel angular pressing (ECAP) [54, 59], accumulative roll bonding (ARB) [60-62], and high-pressure torsion (HPT) $[53,63,64]$ have been extensively utilized for improving the consolidation process and distribution of the particles, several other innovative methods such as torsion extrusion (TE) [65], forward extrusion follows by equal channel angular pressing (ECAP-FE) [66], ECAP with back pressure $[67,68]$, and high pressure double torsion (HPDT) $[69,70]$ have even been more effective. In particular, HPDT was found to enhance distribution of $\mathrm{SiC}$ in a $\mathrm{Cu}$ matrix [69] as well as to improve crystallographic texture homogeneity [71]. Among these bulk SPD 
processes enhancing particle distribution and ensure consolidation, ECAP is the most attractive one due to its simplicity and ability to impair the most homogeneous strain distribution of all.

In general, ECAP process has two channels with the same cross-sectional area. Samples are usually circular or square according to the dimensions of the channels. After applying the appropriate lubricants, the sample is placed in the inlet channel and extruded through the outlet channel using a punch under pressure. The deformation mode in the ECAP process is a simple shear.

In this paper, Al-CNT composites are fabricated using multi-pass ECAP processing method. The content of CNTs was 2 vol.\%, which was added into pure Al matrix. To disperse the CNTs in the matrix, we utilized a combination of attrition milling and ultrasonic waves. The material was characterized in terms of microstructure and mechanical properties. To this end, we performed density measurements using Archimedes method, grain structure characterization using scanning electron microscopy (SEM) and transmission electron microscopy (TEM) characterization, and Vickers hardness tests. The microstructural examinations show that ECAP can synthesize the composites with high degree of microstructural homogeneity. We find that CNTs are effective in improving grain boundary properties by linking the grains via the grain boundaries. This is due to their large aspect ratio. The hardness tests reveal the significant role of CNTs on enhancing the mechanical properties. To facilitate the comparison of enhancement in terms of hardness, Al samples are also processed in the same way. Smaller grain size was obtained in the Al matrix after the addition of CNTs into the composite. We rationalize that this is due to increased dislocation activity over shorter mean free path than in pure Al without CNTs leading to enhanced grain fragmentation and potentially reduced amount of grain growth hindered by CNT links.

\section{Materials and experimental procedures}

In this work, the Al- 2 vol. \% CNT composite samples were successfully fabricated using ECAP. Figure 1 shows steps involved in the process of making Al-CNT composites. Microstructure and mechanical properties of the material are studied and critically compared with the Al samples in the same condition. 

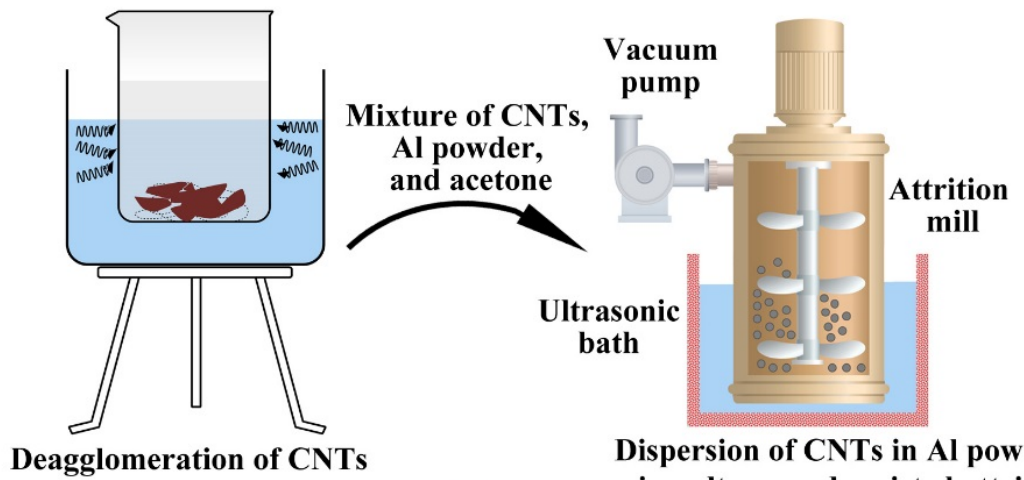
using ultrasonic wave

Dispersion of CNTs in Al powder using ultrasound-assisted attrition milling

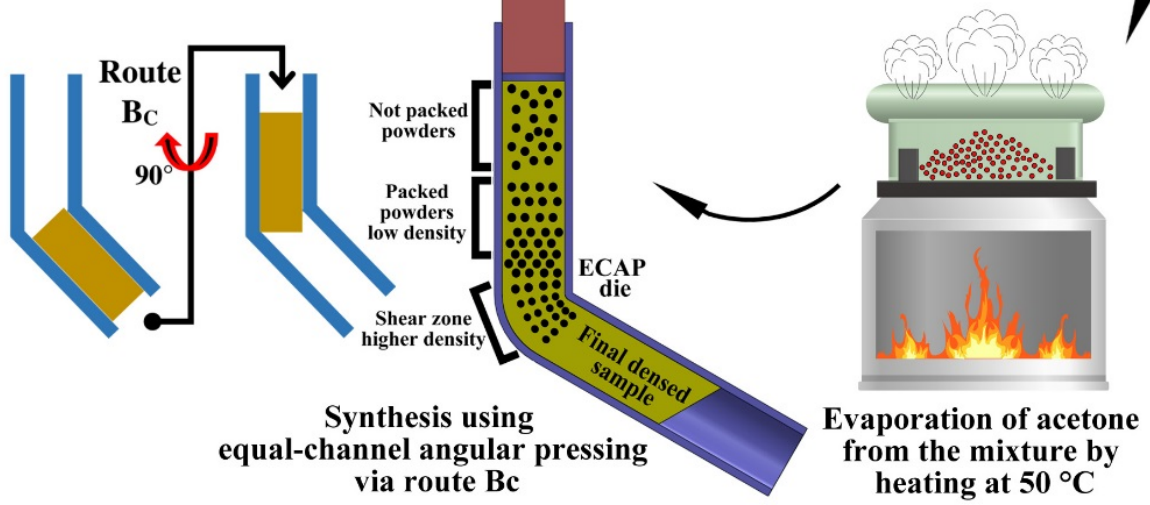

Figure 1. Schematic showing the steps involved in the process of making Al-CNT composites.

\subsection{Starting materials}

Commercially pure aluminum powders with average particle size of $30 \mu \mathrm{m}$ and multiwalled carbon nanotubes (CNTs) with a diameter of 10 to $30 \mathrm{~nm}$ and a length of 5 to $15 \mu \mathrm{m}$ are used as the starting materials. CNTs are produced with catalytic chemical vapor deposition (CCVD) method which revealed $95 \%$ purity and density of $1 \mathrm{~g} . \mathrm{cm}^{-3}$. To investigate the chemical composition of Al powders as well as CNTs, the spectroscopy method is utilized. The results are shown in Table1. In order to remove catalytic impurities from the CNT powders, which mainly consist of nickel and cobalt, an acidic treatment was performed. The acidic treatment consists of treating the CNTs in a solution of nitric acid of $68 \%$ purity for 12 hours which is following by washing the CNTs with distilled water for several times to reach $\mathrm{pH}$ equals to 7. The SEM images of CNTs after acidic treatment and initial morphology of $\mathrm{Al}$ powders are shown in Fig. 2a and b, respectively. The large diameter to length aspect ratio of CNTs ensures a high magnitude of surface energy between the branches of CNTs [72]. As a result, there are many agglomerations in the starting material. In order to reduce these 
undesirable agglomerations, we have explored several methods including treating the CNTs in an acetone solution and/or imposing the ultrasonic waves as described in the next section. We selected acetone because it evaporates quickly, which essential for shortening the time involved in attrition is milling. The short time for attrition milling is important for not existing the flow properties of the material. Additionally, acetone introduces no contamination in the mixture after evaporation.

Table 1 Chemical composition of Al and CNT powders.

\begin{tabular}{|c|c|c|c|c|}
\hline \multicolumn{5}{|c|}{ Aluminum powders } \\
\hline Element & $\mathrm{Al}$ & $\mathrm{Fe}$ & $\mathrm{Si}$ & $\mathrm{Cu}$ \\
\hline Content (\% wt.) & 99.6 & 0.24 & 0.11 & 0.05 \\
\hline \multicolumn{5}{|c|}{ Carbon nano tube powders } \\
\hline Element & $\mathrm{C}$ & $\mathrm{O}$ & Co & Mo \\
\hline Content (\% wt.) & 96.13 & 3.58 & 0.09 & 0.2 \\
\hline
\end{tabular}
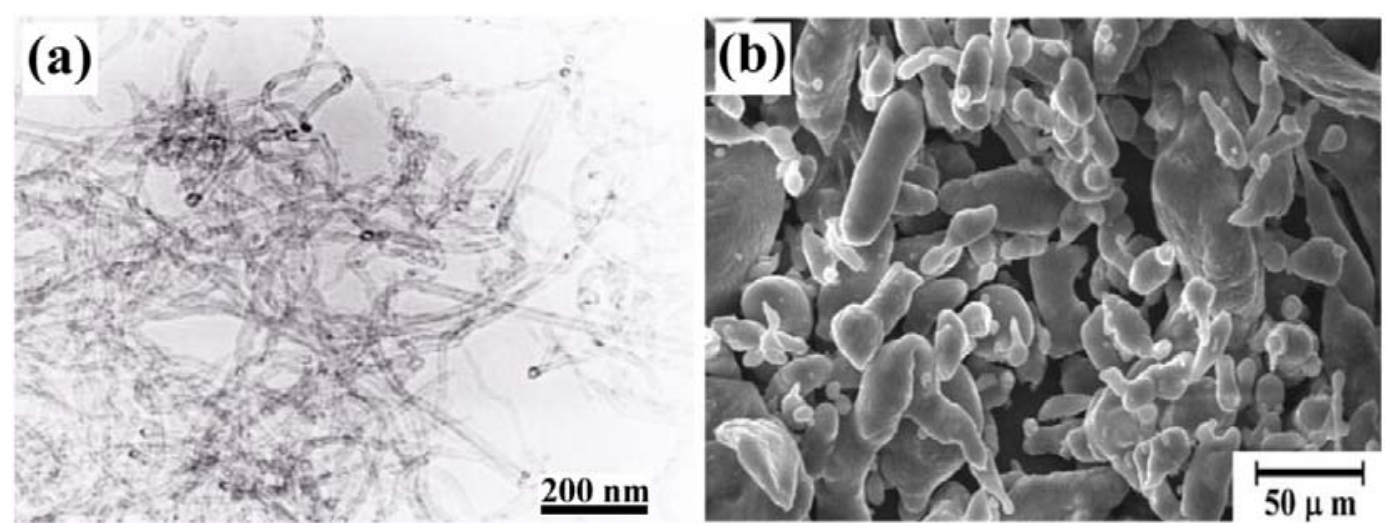

Figure 2. SEM micrographs of starting (a) CNTs after acidic treatment and (b) Al powder.

\subsection{Mixing starting materials}

To assure initial dispersion of CNT particles within the Al matrix, several procedures were explored. The procedures consist of attrition milling process and ultrasonication (see Fig. 1). In the attrition milling, the ball to powder ratio (BPR) was approximately 15 and the milling speed was $500 \mathrm{rpm}$. The milling and ultrasonic time periods were varied to reach the semi- 
solid paste of the mixture. A vacuum pump was attached to the attrition mill chamber and used to accelerate the evaporation of the acetone from the vessel. Finally, the mixture was heated at low temperature $\left(50^{\circ} \mathrm{C}\right)$ to evaporate acetone from it.

Specifically, we investigated 4 procedures for obtaining desirable dispersion of the CNT particles:

1) We started by attrition milling the acid treated CNTs and Al powders in $400 \mathrm{~mL}$ acetone for 2 hours. Figure 3 shows the outcome mixed material where the CNTs can be observed to agglomerations in the mixture.
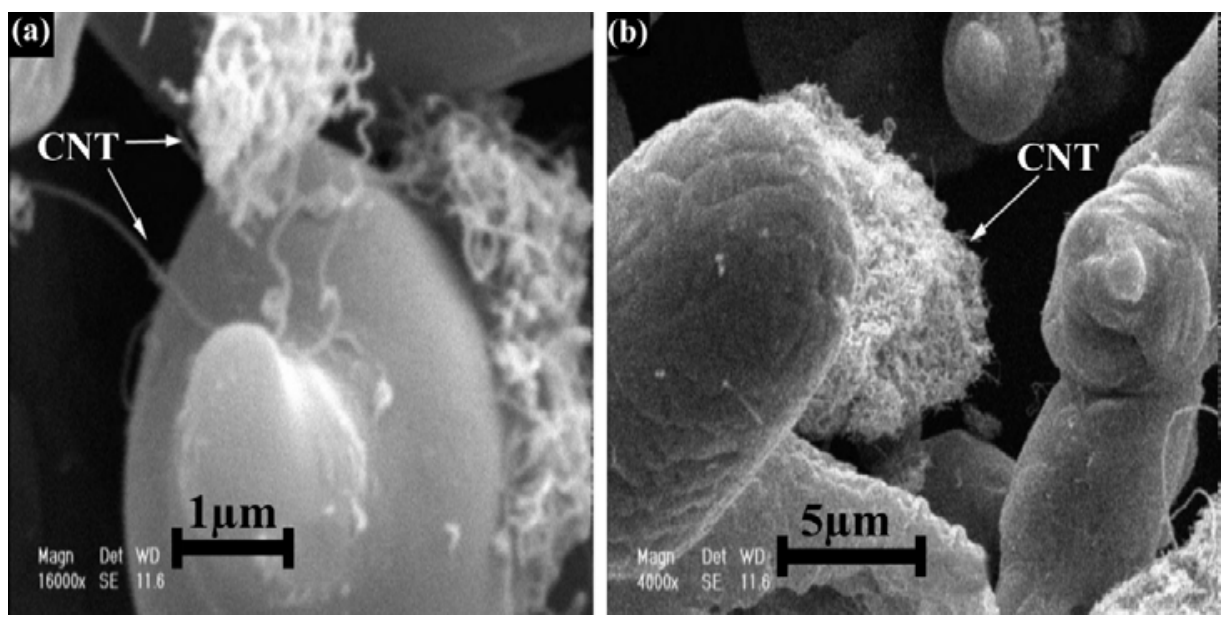

Figure 3. SEM images showing mixed material after attrition milling for 2 hours at (a) 16k and (b) $4 \mathrm{k}$ magnifications. The agglomerations of CNTs can be observed on the Al powder surface.

2) In our next trial, we extended the milling time to 4 hours. The SEM images in Fig. 4 show improvements in terms of reduced amount of CNT agglomerations on the surface of Al powders, which is due to a large amount of strain imposed onto the ductile matrix during the milling process [73]. However, the main issue is that Al powers became severely plastically deformed with flakes, which would limit subsequent processing. It became evidently that the attrition milling by itself cannot produce the desired CNT dispersion and the paste for further processing [45]. 


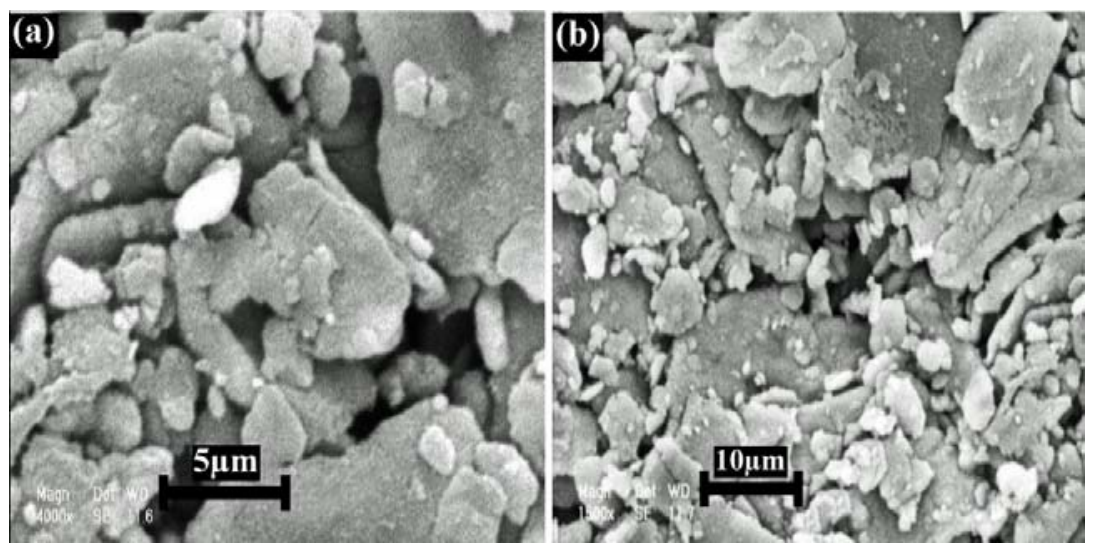

Figure 4. SEM micrographs showing the mixed material after 4 hours of attrition milling at (a) $4 \mathrm{k}$ and (b) $1.5 \mathrm{k}$ magnifications. CNTs appear to be within the Al particles and flakes.

3) In our next attempt, we introduced ultrasonic waves. Here, the CNTs underwent ultrasonic waves for $30 \mathrm{~min}$ in $400 \mathrm{~mL}$ acetone solution. The resultant CNTs solution was then poured into the attrition mill chamber and mixed with Al powders. The mixture was milled while being exposed to ultrasonic waves for 1 hour. Subsequently, the mixed powder was milled without undergoing ultrasonic waves until reaching a semi-solid paste (approximately for additional $30 \mathrm{~min}$ ). Figure 5 shows that the dispersion has improvements compared to the earlier procedures. However, agglomerated CNTs on the Al powders surfaces can still be found.
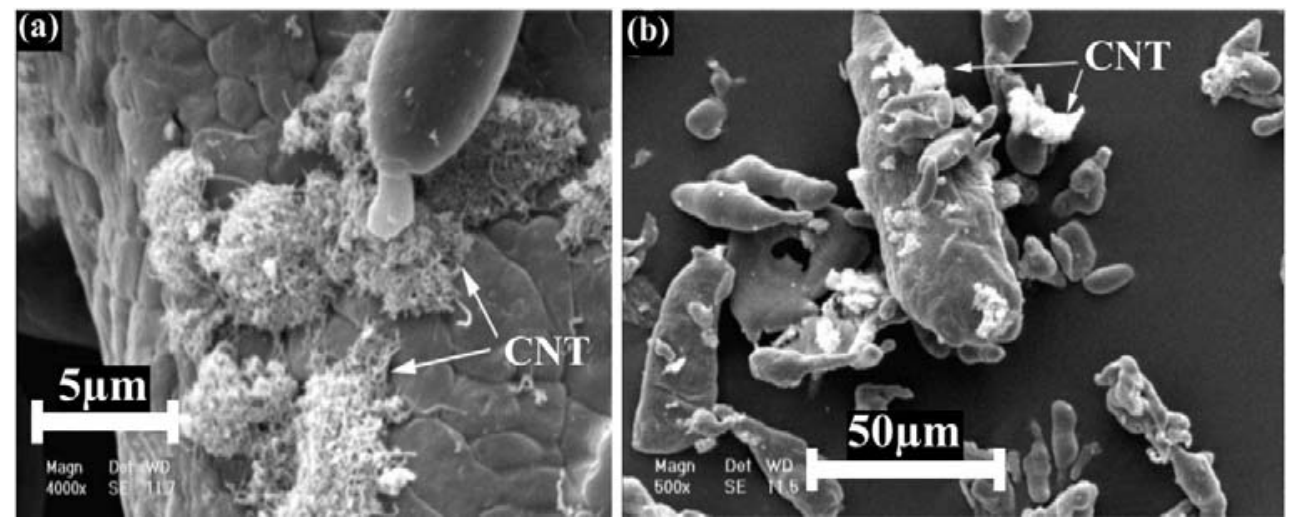

Figure 5. SEM micrographs showing dispersion of CNTs within Al powder after 30 min of ultrasonic treatment, $60 \mathrm{~min}$ of attrition milling under ultrasonic waves, and $30 \mathrm{~min}$ of attrition milling at (a) 4k and (b) 500 magnifications. Agglomerations can be observed.

4) The final procedure consisted of ultrasonic wave treatment during the entire attrition milling process. The SEM micrographs shown in Fig. 6 are subset of many that we observed. Our conclusions are based on the evaluation of many images. Figure 6 
shows the distribution of the CNTs after mixing process, which is not the final step in creating the material. This procedure was found to work well for preparing the starting materials before the ECAP consolidation. The severe plastic deformation method, ECAP, consolidates the sample while further improving the distribution by imparting large plastic strains.
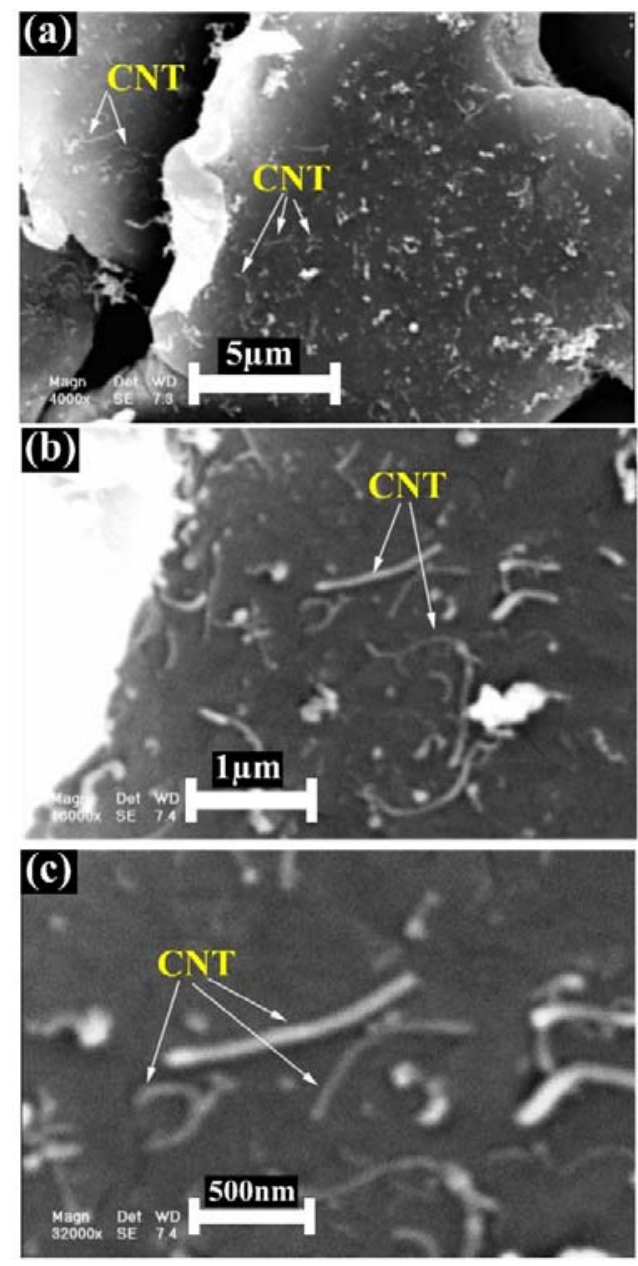

Figure 6. SEM micrographs showing improved dispersion of CNTs in Al matrix after simultaneous ultrasonic wave and attrition milling action for 120 min at (a) 4k, (b) 16k, and (c) $32 \mathrm{k}$ magnifications.

\subsection{Processing of Al and synthesis of Al-CNT composites using ECAP}

The prepared mixture was consolidated using the equal channel angular pressing (ECAP) process of severe plastic deformation (SPD). The ECAP die had $20 \mathrm{~mm}$ channel diameter with the geometrical angles of $\varphi=120^{\circ}$ and $\psi=20^{\circ}$ where $\varphi$ is channel angle and $\psi$ is outer corner angle. Because the route $\mathrm{B}_{\mathrm{C}}$ (see Fig. 1) is known to impart better strain 
homogeneity then other ECAP routs and is more effective on the grain refinement [74-77], this route was selected for the present study. The punch speed was $0.8 \mathrm{~mm} \cdot \mathrm{sec}^{-1}$. The effective strain after each pass with the above summarized die geometrical is estimated to be 0.67 using $\bar{\varepsilon}=\frac{2}{\sqrt{3}} \cot \left(\frac{\varphi}{2}\right)[78-80]$. Schematic showing the locations of microstructural characterization on the sample cross-sectional areas is shown in Fig. 7.

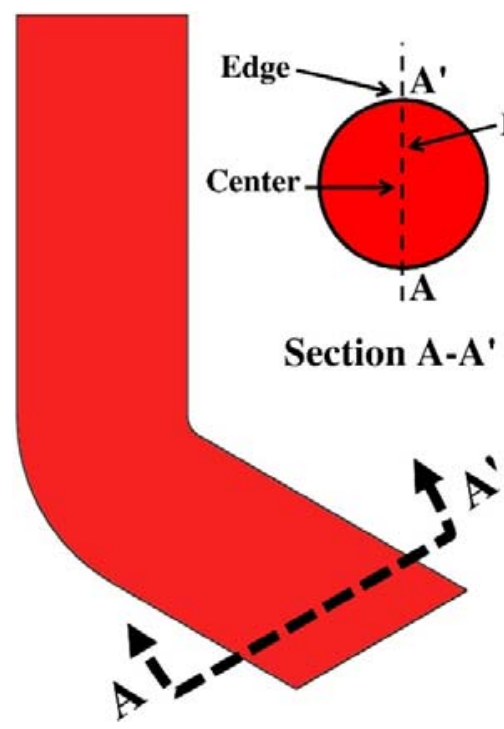

Figure 7. Designations of investigated locations on the ECAPed sample.

\subsection{Microstructural characterization}

The distribution of the CNTs in the Al matrix before and after ECAP process as well as the grain shape and size and the porosity were evaluated in a PHILIPS XL30 scanning electron microscopy (SEM). For SEM, the samples were mechanically prepared using grinding and polishing procedures. A series of $\mathrm{SiC}$ papers ranging from 120 to 4000 grit were used to grind the samples. After grinding, the samples were polished on a cloth using steps of $3 \mu \mathrm{m}$ to $1 \mu \mathrm{m}$ diamond paste. The investigated surfaces were perpendicular to the exit channel axis as depicted in Fig. 7.

Transmission electron microscopy (TEM) characterization was performed in FEI/ PHILIPS EM208S operated at $100 \mathrm{kV}$. Using TEM, we determined the grain size and further studied CNTs distribution. The samples were prepared by a conventional mechanical method which is using 120 to 4000 grit $\mathrm{SiC}$ papers followed by ion milling. 
Density was measured by Archimedes method. Following the ASTM C20.00, the samples were kept suspended in distilled water at $100^{\circ} \mathrm{C}$ in for 2 hours. To obtain the density of each sample, three mass values are required per protocol: the mass in the dry state $\left(m_{d}\right)$, the mass in water when the sample is suspended $\left(m_{s u}\right)$, and the mass of the sample when it is saturated with water $\left(m_{S a}\right)$. The density can then be calculated using: $\rho=\frac{m_{d}}{m_{S a}-m_{S u}}$.

\subsection{Hardness testing}

To evaluate the mechanical properties of CNT composite samples,Vickers hardness tests were carried out on the samples processed using ECAP at a different number of passes. The Vickers hardness test was also performed to evaluate the homogeneity of the structure in terms of mechanical properties. The force and loading rate were $100 \mathrm{~g}$ and $2 \mathrm{~g} \cdot \mathrm{sec}^{-1}$, respectively while the dwell time was 15 seconds.

\subsection{Finite element simulations of ECAP}

To better understand the distribution of strain in the ECAPed samples, we performed a 3D finite element analysis using ABAQUS/Explicit of the ECAP process [81]. The geometrical dimensions and mechanical properties of the specimens were the same as those used in the experiments. The mechanical properties of the raw material were based on the compression tests carried out on the AA1050 samples. The height to diameter ratio of the samples was 1.5 and tests were performed at constant crosshead speed of $0.2 \mathrm{~mm} \cdot \mathrm{sec}^{-1}$. The following flow stress-strain relationship fitted well the data: $\sigma=106 \varepsilon^{0.345}(\mathrm{MPa})$. This relationship was used in the FEA program for estimating the strain fields over the sample after one ECAP pass. To this end, 8-node linear brick elements (C3D8) and 4-node 3D bilinear rigid quadrilateral elements (R3D4) were used to mesh the billet and the rigid parts, respectively [81]. Similar simulation setup was used in an earlier study [82]. The predicted strain fields were crosscorrelated with the hardness values as will be discussed later in the paper.

\section{Results and discussion}

\subsection{Pore distribution}

Material samples synthesized using powder metallurgy typically contain pores in the microstructure, which is a significant issue $[65,67,69,74,83,84]$. In this study, the pore structures of Al and Al-CNT composite samples were investigated in the material as a function of ECAP passes and the geometric location in the sample (Figs. 8 and 9). As it can be seen, in 
both instances the pores increase from the surface to the center. The reason for this can be attributed to the strain level, which varied due to the friction between the ECAP channel wall and the sample. The presence of the friction causes non uniform strain distribution unlike the theoretical equation is predicting. As will be shown in the FEA simulation results, moving towards the center of the sample, the effect friction diminishes. As a result, more pores can be expected at the center location. The composite samples exhibit more pores than the pure $\mathrm{Al}$ samples. The densification of the composite system is suppressed by the presence of an excluded volume around the hard powder particles. The soft particles (the Al powder in this study) must undergo additional deformation in order to fill this volume. Geometrically, the imparted load cannot be totally transmitted to the CNTs that supports a portion of the load. Agglomerates of pores were found in many places after the early passes, with subsequent pore collapse and homogenization with the increasing number of ECAP passes. This is due to a combined effect of (i) hydrostatic pressure inside the entry channel and (ii) shear deformation between the entry and exit channels. With the matrix plastically deforming the residual porosities is reducing (filling the excess volumes around the CNTs) and the density eventually reaches near to the theoretical density. In addition, the clusters of CNTs are being broken and thus less agglomerated particles remain in the microstructure, which can pin the grain boundary motion contributing to the overall strengthening of the composite $[54,85,86]$.

Achieving the fully dense microstructure is challenging. One would likely need perform many more ECAP passes while introducing a modification of having back pressure at the exiting channel [67] and even consider conducting the consolidation process at a higher temperature.
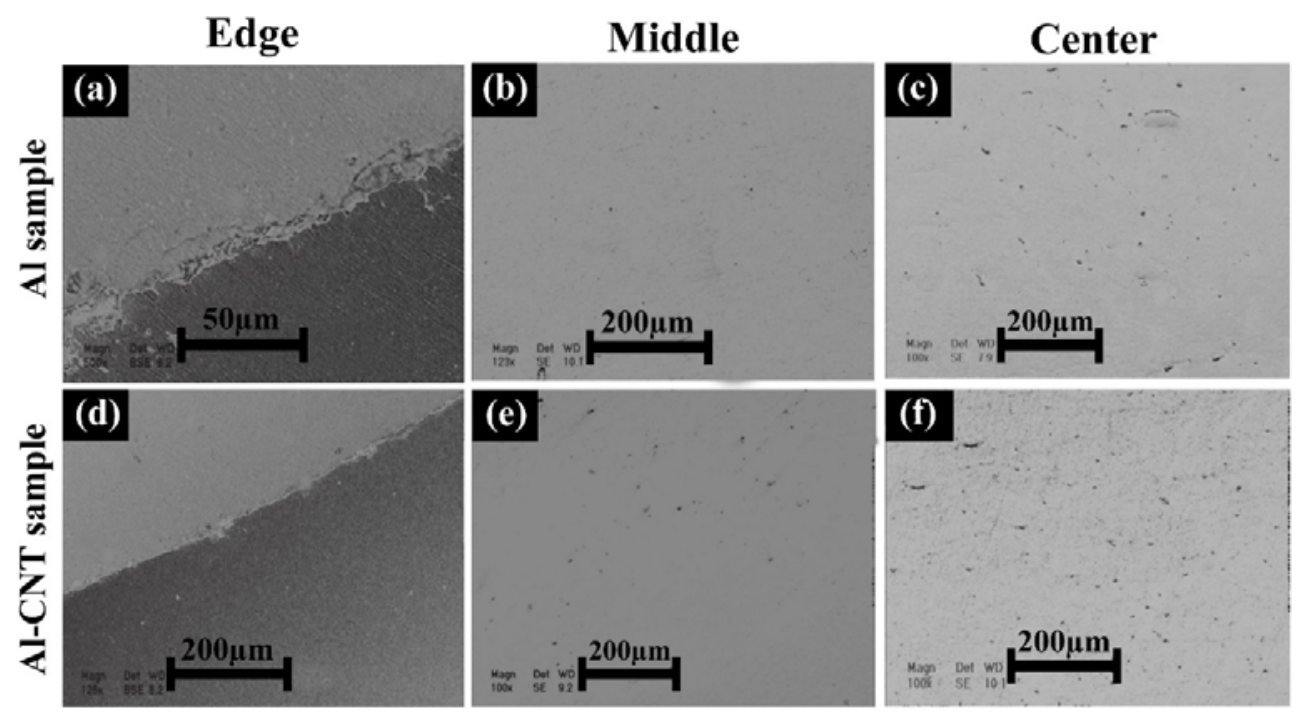
Figure 8. SEM micrographs showing pore evolutions as a function of location in Al and AlCNT samples after 4 passes of ECAP.
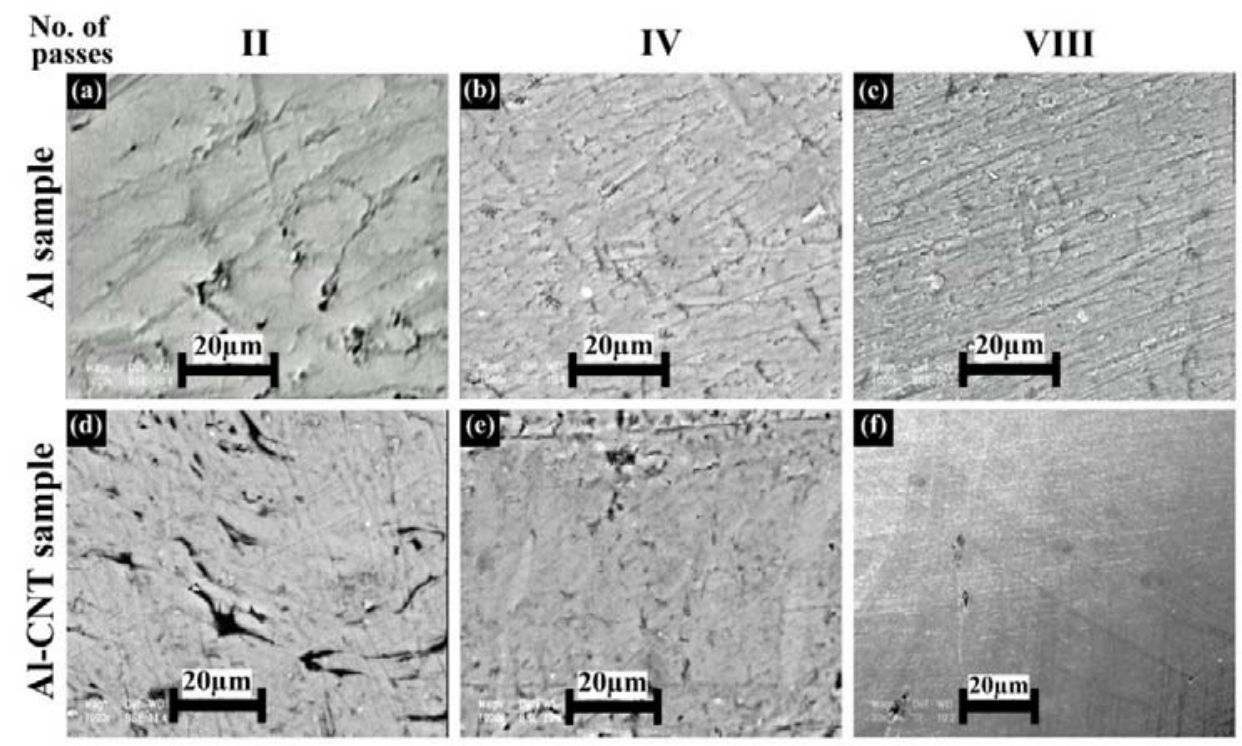

Figure 9. SEM micrographs showing pores evolution as a function of number of passes (equivalent of different strain levels) in $\mathrm{Al}$ and Al-CNT samples.

To quantify the effect of the number of passes on the pore evolution, density measurements were performed. Fig. 10 shows the relative density (RD) graph based on the number of passes for both Al and Al-CNT samples. The RD for composite sample is less than the Al sample at the same number of passes which is consistent with the microstructural observations in Fig. 8 and 9. By increasing the number of passes, the RD increase which is due to higher values of strain imposed to the sample. This can be justified with consolidation mechanisms under large deformations. These mechanisms include changing the shape of the powders due to the plastic deformation following by breaking the surface ridges of the powder surface and penetrating into the pores spaces which eventually results in changing the shape of the pores due to the plastic deformation [87]. The effect is larger in the Al-CNT composites. The reason that the density of the Al-CNT samples is lower than the theoretical one can be due to the incoherency of CNT particles with the Al matrix which is associated with the pores around the CNT particles. These factors reduce ability of the material to flow plastically [88]. 


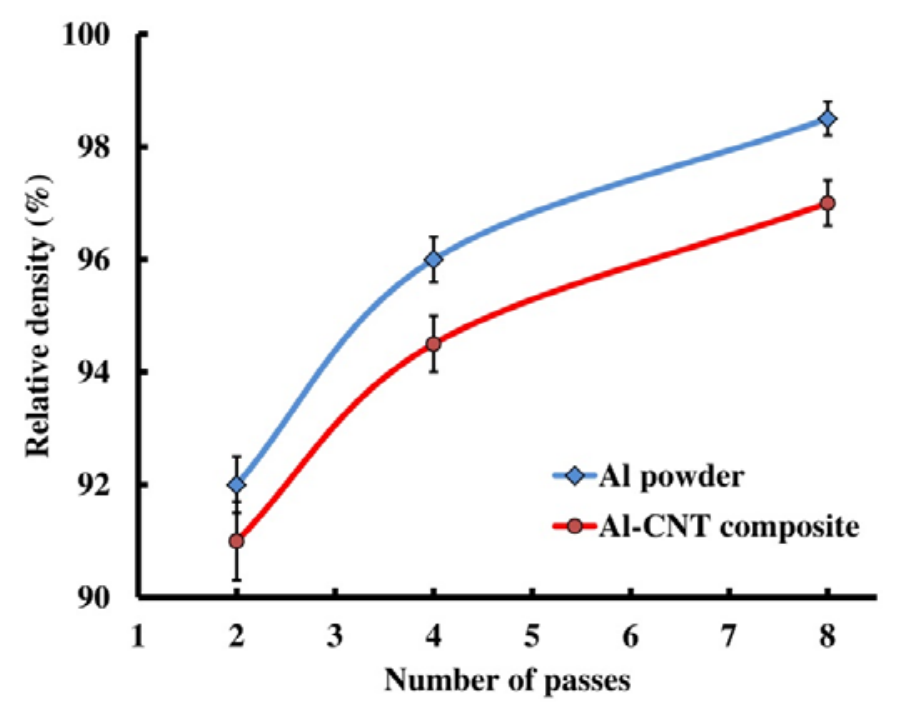

Figure 10. Evolution of density as a function of number of passes in Al and Al-CNT composite samples.

\subsection{CNTs and grain structure as revealed in SEM and TEM}

To observe the CNTs in Al matrix, after the fourth and eighth pass in the ECAP process the samples were treated for 30 seconds in Nitric acid solution (68\%), the treatment which corroded the primary particle boundaries (PPBs) but not the grain boundaries inside powder particles. The CNTs were revealed using this treatment since Nitric acid has no effect on them. The treatment was more effective with the increasing amount of strain present in the material [84]. The results can be seen in Fig. 11. The CNTs seem to create a network bridging the particles and grain boundaries. This is indeed believed to be one the most important factor in enhancing mechanical properties using CNTs. For example, the effect of CNT on fracture has been studied in $[12,86,89,90]$. The CNTs network over grain boundaries was found to be the main toughening mechanism suppressing crack nucleation and growth. As the deformation continues, the matrix plasticity exhausts and cracks start propagating in the matrix which the cracks finally confront the CNTs. As a consequence, the CNTs fracture starts. 

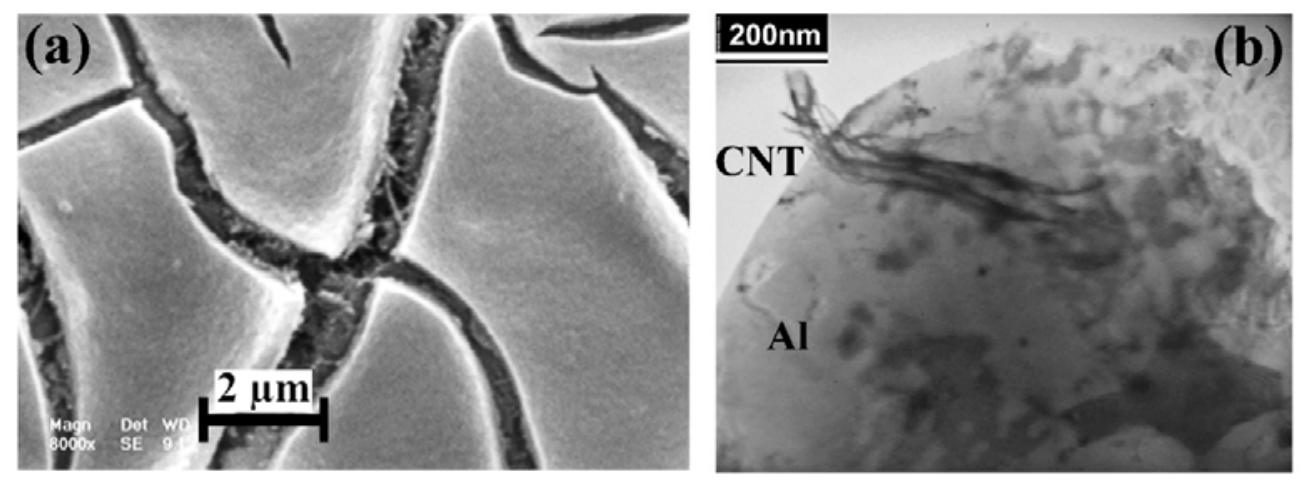

Figure 11. (a) SEM micrograph showing corroded grain boundaries by application of the nitric acid solution over the composite after 4 passes of ECAP, (b) TEM image showing particle boundary and CNT links in Al-CNT composite after 4 passes of ECAP.

Figure 12 shows the bright field image of the sample after eighth pass of the ECAP process. As the selected area diffraction (SAD) shows, there is a presence of large grain size relative to the electron beam diameter which indicates a uniform grain size distribution [75]. Figure 12 also shows that grains are equiaxed. This demonstrates the suitability of the Bc route to achieve a very high strains resulting in substantial grain refinement [91]. Occurrence of subgrains in the structure with high angle inside the original grain demonstrates that primarily the grain refinement in the structure follows the theory of dislocation cell walls leading to the creation of new grain boundaries out of the dislocation cell walls [92]. These grains oriented close to the original parent grains and they can always be found as a group like the one at the bottom of Fig. 12. A fine grain size of about $1 \mu \mathrm{m}$ was achieved. Further grain refinement in pure $\mathrm{Al}$ is known to be hindered by occurrence of grain growth [93, 94]. However, the issue of grain growth can be relaxed by creating a composite of Al and CNTs, as done in the present work. CNTs are believed to create pile ups of large dislocation density that facilitate more grain refinement than in pure $\mathrm{Al}$. 


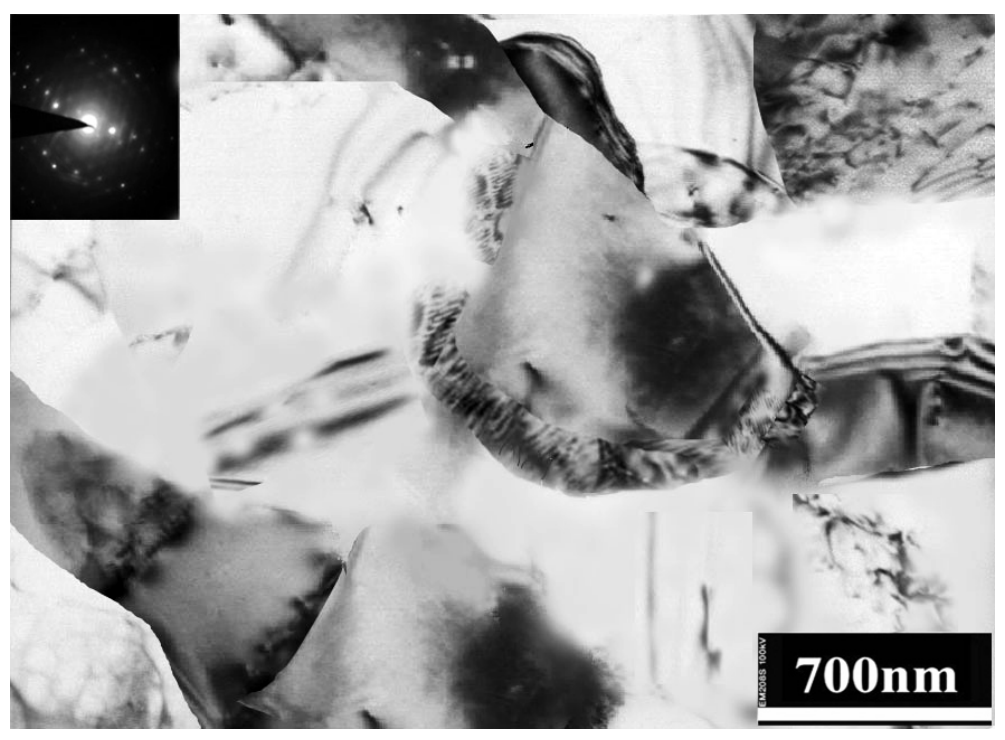

Figure 12. Bright field TEM image of pure Al sample after 8 pass of the ECAP.

TEM micrographs of the composite samples are shown in Fig. 13a and b. The CNTs seem to be embedded in the grain boundaries and grain boundaries junctions of the Al matrix in Fig. 13a. At the early passes of ECAP, there are many agglomerates at the high energy sites of the composites which are mostly PPBs (see Fig. 13a). The particle clusters are deformed together with the matrix. They are elongated in the direction of the shear zone in ECAP after the first pass $[67,68]$. As the route $\mathrm{B}_{\mathrm{C}}$ rotating the sample after each pass $90^{\circ}$ around the sample axis, this orientation of the particles are randomized in the microstructure after a certain amount of passes (see Fig. 13b). Therefore, a final microstructure is very often characterized by the presence of "particle-rich bands" which still degrades the formability of the composites [63, 69]. In the case of ECAP, however, there is no deformation of the dense particle clusters, as their aspect ratio distribution does not change even after very high strains. The particles are debonded from the surface of dense particle clusters and move into the particle-free matrix (cluster erosion). Thus, no particle-rich bands appear in the microstructure after 8 passes of ECAP and a very homogeneous particle distribution is observed as shown in Fig. 13b. Such behavior can be explained by the presence of very high hydrostatic stresses. As was shown in $[95,96]$, these high hydrostatic stresses in the entry channel suppress any plastic flow in highly concentrated particle clusters, even at very high levels of plastic strain. In other words, each dense CNT particle cluster behaves like a single hard particle that is "eroded" by the matrix 
during ECAP. However, we observed regions of agglomerates which are resulting from the locations close the ECAP die wall that have more friction and induce higher values of strain.
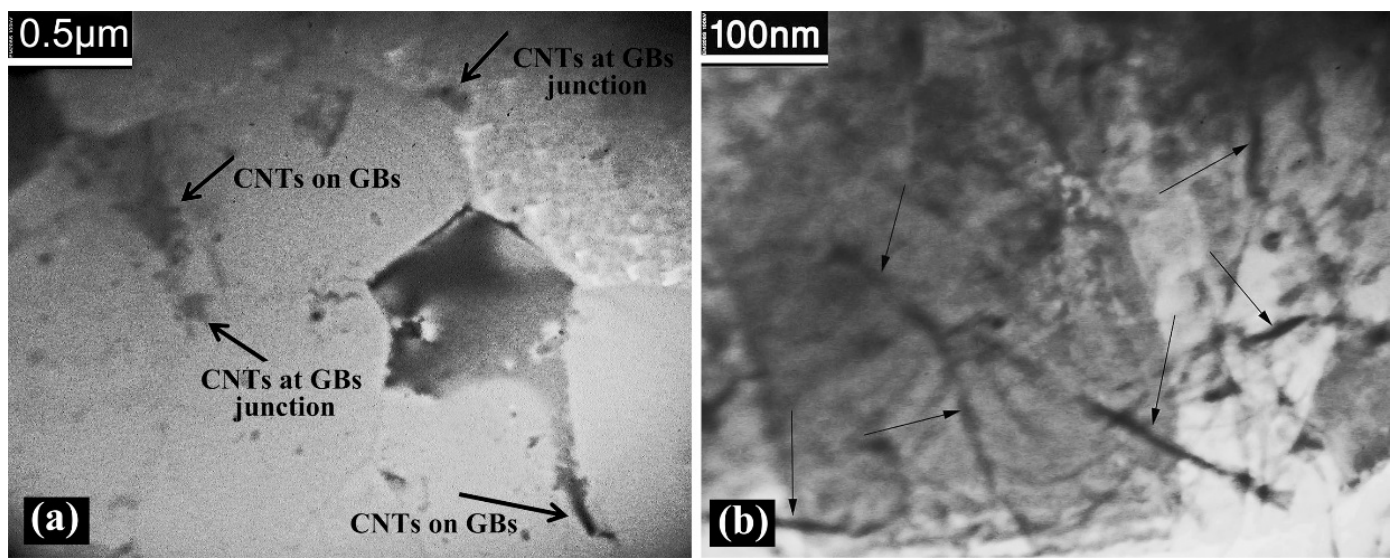

Figure 13. (a) TEM image showing agglomerates of CNTs within the Al matrix after 2 pass of ECAP. CNTs appear to fill the high energy spots i.e. grain boundaries (GBs) and GBs junctions. (b) TEM image showing the distribution of CNTs on the Al matrix surface after 8 pass of ECAP. Arrows are pointing to CNTs.

\subsection{Hardness of Al and Al-CNT composites processed by ECAP}

Three strengthening mechanisms have been reported to govern enhanced mechanical properties of Al-CNT composites: load transfer, generation of dislocations by thermal mismatch, and stored dislocations resulting from severe plastic deformation $[11-14,16]$. The strengthening via load transfer mechanism is due to volume fraction and aspect ratio of particles in a metal matrix composite. The thermal mismatch mechanism is significant at high temperatures processing which increases the initial dislocation density. Increase in stored dislocations is generated by the plastic deformation during making the material by ECAP. As ECAP was performed at room temperature, the thermal mismatch mechanism is not expected to be significant. Finally, due to the comparably good stability of CNTs in the solid-state Al matrix at the present consolidating process, the solution strengthening and the resultant precipitation strengthening can be neglected in Al- CNT composites. Therefore the dominant mechanisms for strengthening are stored dislocations and large content of grain boundaries resulting from grain refinement. 
During plastic deformation, initially existing dislocations generate new dislocation by mutual interference, thus increasing the dislocation density. This phenomenon leads to an increase in the strength, namely due to strain-hardening, which is directly proportional to density of dislocations [97]. It was mentioned previously that the CNTs have high hardness and elastic modulus and do not deform plasticity. Therefore the stored dislocations are in the Al matrix. The dispersed CNTs inhibit propagation of dislocations $[11,98]$, thus improving the strength of the composite, which can be explained using the Orowan looping system and reduced mean-free-part of dislocations. The decreases in grain size and inter-particle spacing due to grain refinement increases content of grain boundaries which is again a strain hardening mechanism for the composite. Grain refinement also decreases dislocation mean free paths leading to more strengthening. In addition, $\mathrm{Al}$ is a high stacking fault energy (SFE) material which after a certain amount of straining the hardening will be saturated and further straining does not increase the strength due to dynamic recrystallization (DRX) which is occurring by the nucleation and growth mechanisms of grains with high angle grain boundaries (HAGBs) [99-101]. Introducing CNTs postpones the recrystallization and promises higher strength to be obtained.

Vickers hardness distributions of pure $\mathrm{Al}$ and Al-CNT samples from edge to the center of the samples produced by ECAP after fourth pass are shown in Figure 14. As it can be seen, at the edge of the samples in both samples the hardness value is maximum while moving to the center showing a decreasing trend in hardness value. This can be explained by the presence of pores in the microstructure and the strain gradient in the ECAPed sample from the die wall to the center.

Moving from the center toward the edge of the samples the pores in the samples will be diminished and this causes in the observed hardness distribution trend. As hardness is well considered to be the resistance of the material's surface against penetration, the presence of pores on the surface reduced the surface plasticity and eventually decreased the hardness. 


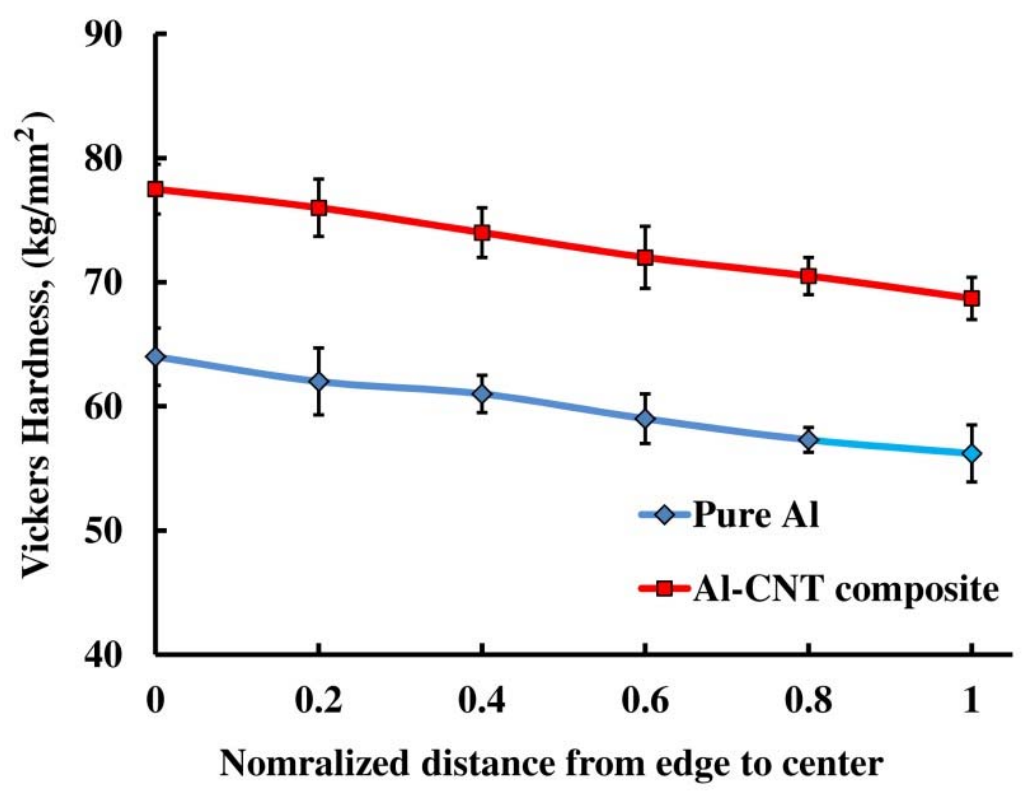

Figure 14. Vickers hardness from edge to the center for samples of pure Al and Al-CNT composite after 4 pass of ECAP.

The hardness distribution can also be explained by the trend in the plastic strain accumulated in the material. The hardness and strain values have direct relationship [71, 82, $83,88,102-104]$. To verify the strain trend, the finite element analysis results were shown in Fig. 15: perpendicular and parallel to the axis of the exit channel. As indicated in the figure, the strain is the lowest in the vicinity of the die away from the bottom wall. The strain reaches its maximum in the vicinity of the walls at the top. The reason for such strain distribution is existence of the dead zone at the bottom of the die where two channels are intersecting. In this area, the material would not move and the rest of the materials will flow on top of this area which results in increasing the outer corner angle $(\psi)$ [105]. Increasing in $\psi$ will lead to less strain as can be inferred from the following equation $\bar{\varepsilon}=\frac{2}{\sqrt{3}} \cot \left(\frac{\varphi}{2}\right)$ or its extended version $\bar{\varepsilon}=\frac{2 \cot \left(\frac{\varphi}{2}+\frac{\Psi}{2}\right)+\Psi \csc \left(\frac{\varphi}{2}+\frac{\Psi}{2}\right)}{\sqrt{3}}[79]$, where $\varphi$ is channel angle and $\psi$ is outer corner angle. 

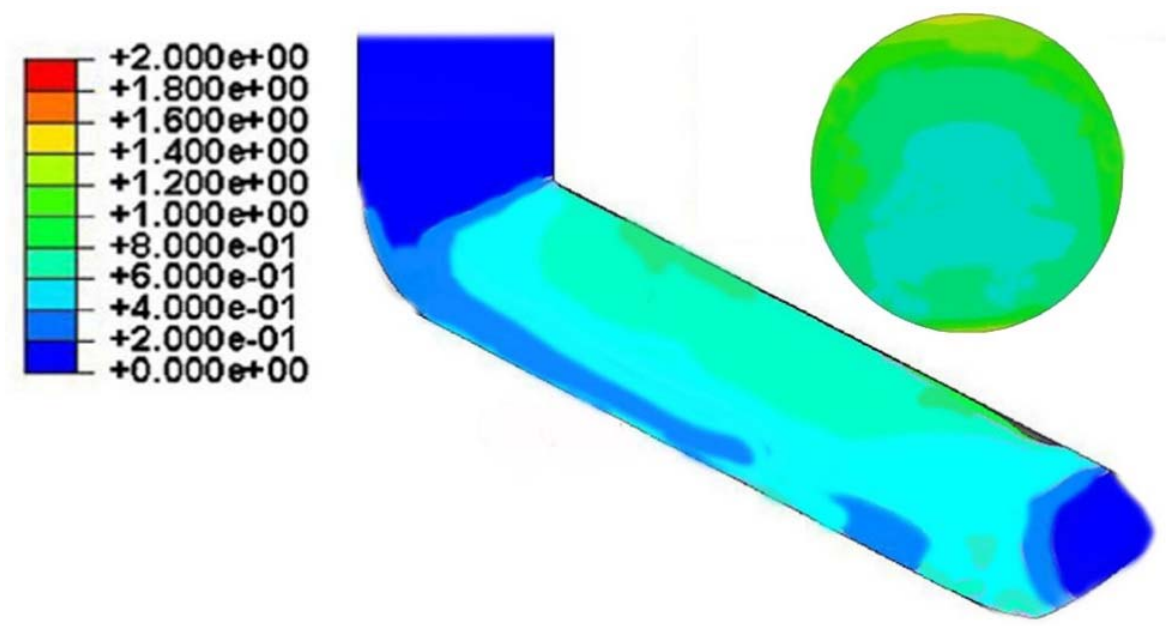

Figure 15. Predicted equivalent plastic strain contours perpendicular and parallel to the axis of the exit channel after one ECAP pass.

The pure Al and Al-CNT composite samples hardness distribution after eight pass of ECAP is shown in Fig. 16. The hardness values of the material after receiving large amount of strain (eight passes) is showing more homogeneity than the one obtained in Fig. 14 after 4 pass. The homogenization of hardness after large amount of strain can be explained by saturation in strain hardening and structural changes. Additionally, recovery mechanism will be activated earlier in high strain regions, which helps balancing completion between refinement and recovery leading to more uniform structure after suffering high strain levels $[68,106]$. The dynamic recovery operations by dislocation climb and cross slip. Since dislocation climb mechanism is a diffusional process which require high temperatures, this mechanism is not expected to dominate because the consolidation process in this work was performed at room temperature. The cross slip mechanism occurs by the screw dislocations and is highly dependent on the SFE value of a material. The greater the amount of the SFE the easier is the cross slip [107]. Al is a high SFE material meaning that the cross slip mechanism should be dominant. 


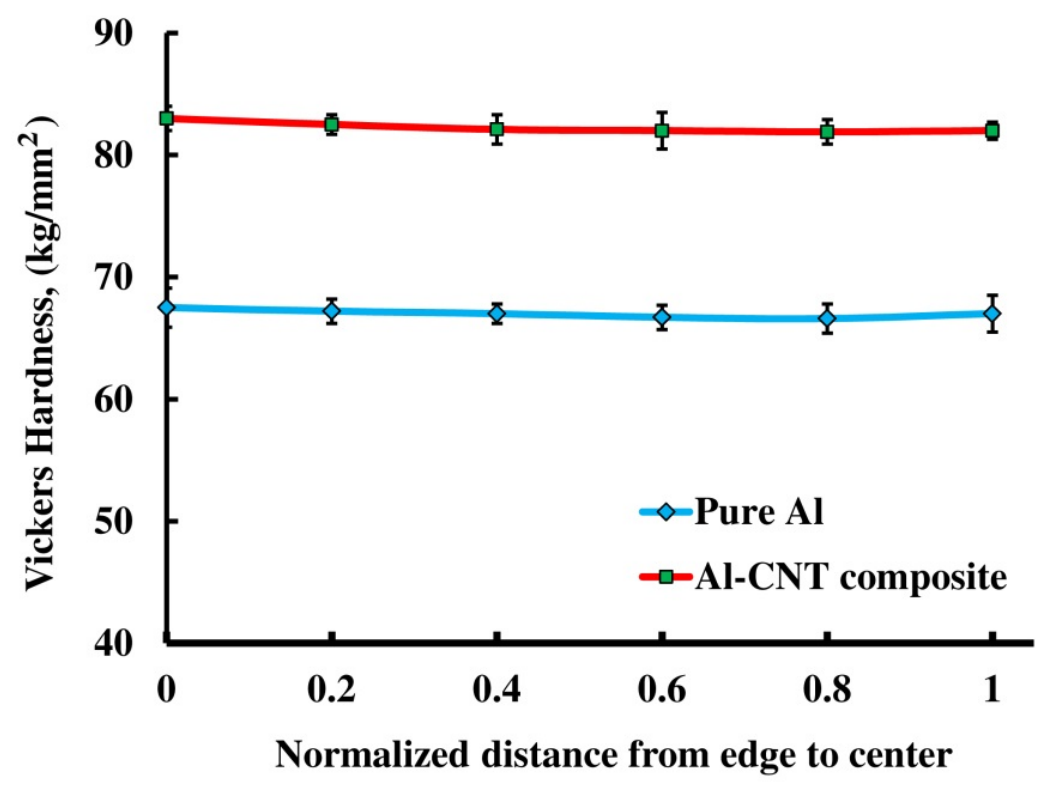

Figure 16. Vickers hardness from edge to the center of pure Al and Al-CNT composite samples after 8 pass of ECAP.

The average amount of the hardness values for $\mathrm{Al}$ and Al-CNT composite samples in different passes is shown in Fig. 17. As shown in the diagram, the hardness values of composite samples are greater than those of pure Al. The reason is due to the presence of hard reinforcements, CNTs, influencing dislocation glide and grain refinement as explained above [25]. It should be noted that the amount of reinforcing material added is low (i.e. 2 vol.\%) but due to the enormous number of nanometer-scale CNTs reducing the slip distances as well as the particle distances the effect on hardness in substantial. As a result, the rate of work hardening is higher than in pure $\mathrm{Al}$, which enhances the hardness values in the composite samples.

Porosity present in the samples reduces with strain. Figure 17 shows an increase in hardness value as the number of ECAP passes increases. It is understood that after the first pass in the ECAP, a significant increase in the hardness of Al and Al-CNT composite samples occurred while by increasing the number of passes, the rate of increase has dropped in both samples. This may be due to the fact that after the initial passes (like 1 or 2), the major displacements that are imposed to the matrix (the strain by plastic deformation) are utilized for shrinking the pores size which leads to a fast increase in density (consolidation) after early passes of SPD process while with the progress of the ECAP process, the grain refinement 
mechanisms and microstructural development take into place to be significant but less effect than the porosity collapse on the hardness values. This leads to lower increasing rate of hardness value after a certain number of passes [108].

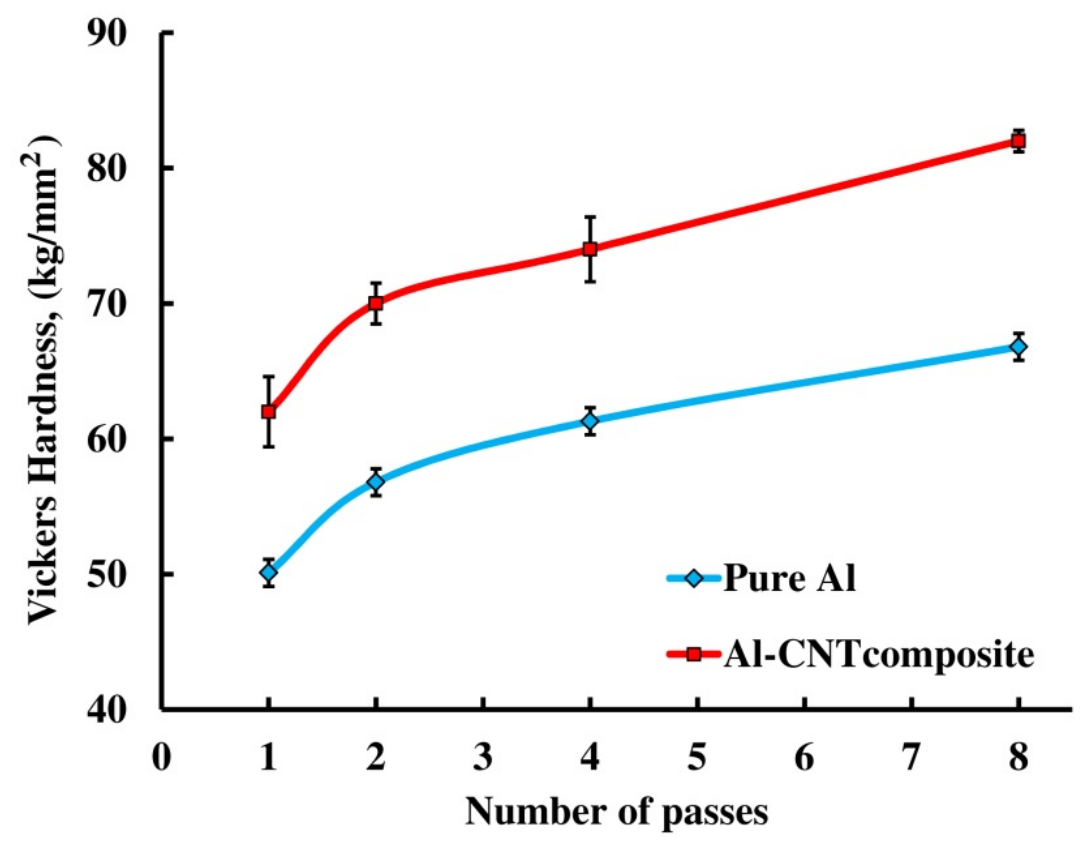

Figure 17. Average Vickers hardness values of pure Al and Al-CNT composite samples produced by ECAP after 1, 2, 4, and 8 passes.

\subsection{Compression test of Al and Al-CNT composites processed by ECAP}

Figure 18 shows results of the compression tests performed on the consolidated powder samples. To facilitate further comparison, we show the flow stress of the pure bulk Al manufactured using 8 ECAP passes [109]. Evidently, the ingot material shows more work hardening and a higher ultimate stress than the consolidated pure $\mathrm{Al}$ from powder. This can be attributed to the fact that the consolidated samples contain a certain level of porosity that weakens the matrix. Most of the plastic deformation imposed on the sample collapse the porosities, and as a result, a lesser amount of plastic strain goes into the powder samples than in the bulk material samples for a given number of passes. Therefore, the bulk material is expected to have a finer grain structure resulting in a higher flow stress. 


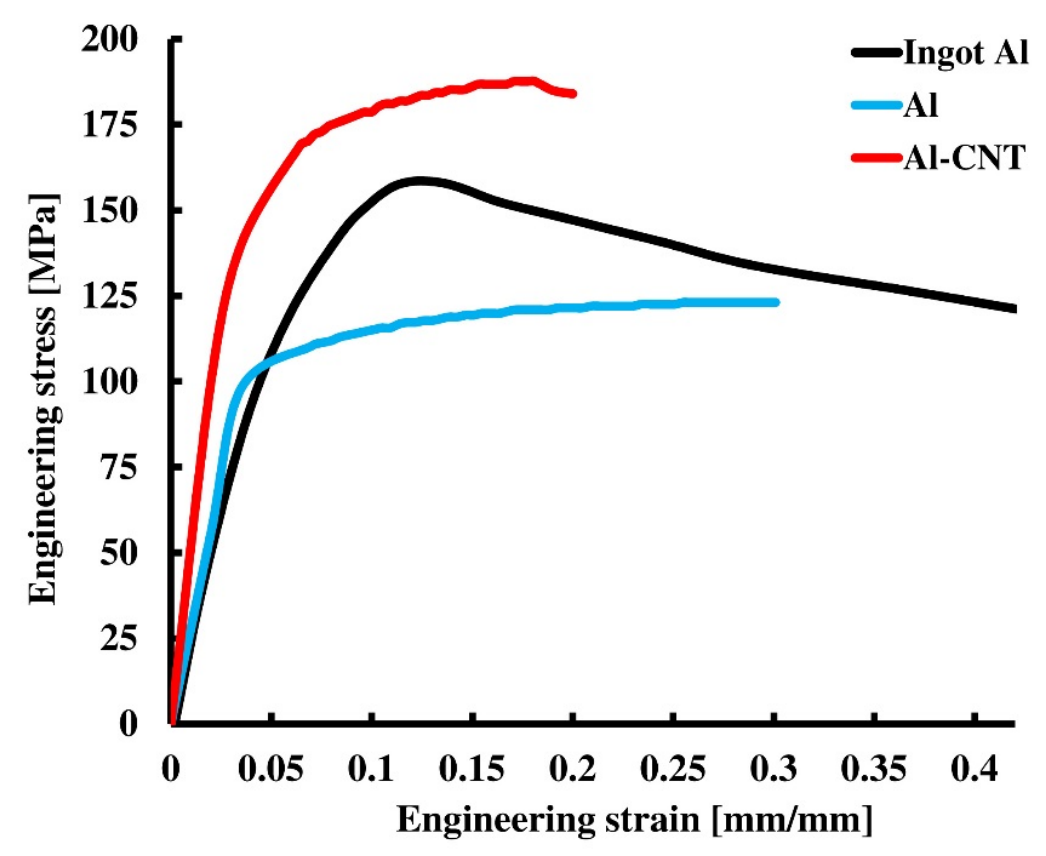

Figure 18. Engineering stress-strain curves of pure Al, Al-CNT composite, and pure ingot Al [109] samples produced by ECAP after 8 passes.

In Fig. 18, an increase in the strength and elastic modulus of the composite samples can be observed. This is due to the CNT reinforcement content and the underlining strengthening mechanisms. Introducing the CNT interfaces between the CNTs and the matrix produces more dislocations in the composite sample, as CNTs act as obstacles to the motion of mobile dislocations. The created pile-ups lead to an increase in the work hardening, which results in the overall increase in the strength of the composites. Moreover, the CNT-reinforced composites have finer grain size that pure Al processed using the same number of ECAP passes [110-112]. The hardening mechanisms overcome the effect of the larger content of porosities in the CNT-reinforced composite than in the pure $\mathrm{Al}$ samples.

\section{Conclusion}

Metal-matrix composites consisted of 2 vol. \% CNTs and Al were successfully synthesized using Bc route of equal-channel angular extrusion (ECAP) to a high level of microstructural homogeneity. To facilitate comparison of microstructure and hardness, samples of Al were processed under the same ECAP conditions. The composite material was found to exhibits $20 \%$ increase in hardness relative to the $\mathrm{Al}$ samples. The results demonstrate 
that as small volume of CNTs as $2 \%$ can have significant effects on hardness when a high degree of homogeneity in their distribution is achieved. The key step in arriving at high level of homogeneous distribution of CNTs within Al was preparation of the powder using simultaneous attrition milling and ultra-sonication processes. Microstructural examinations by SEM and TEM showed that the material reached the high degree of homogeneous state in terms of CNT distribution, porosity distribution, and grain structure after eight ECAP passes. Additionally, Vickers hardness measurements demonstrated absence of hardness gradients across the material confirming the high degree of microstructural homogeneity. Good dispersion of CNTs in the matrix is essential for hardness since CNTs act as obstacles to glide of mobile dislocations, which ultimately lead to more grain refinement. These two mechanisms are responsible for higher hardness values of the composite than pure $\mathrm{Al}$.

\section{Acknowledgements}

HZ, MRT, and MM would like to acknowledge the financial support of Isfahan University of Technology. MK gratefully acknowledges support by the National Science Foundation under grant No. CMMI-1541918.

\section{References}

[1] M.R. Basariya, V. Srivastava, N. Mukhopadhyay, Materials \& Design, 64 (2014) 542-549.

[2] Q. Liu, L. Ke, F. Liu, C. Huang, L. Xing, Materials \& Design, 45 (2013) 343-348.

[3] M. Habibi, A. Hamouda, M. Gupta, Composites Science and Technology, 72 (2012) 290298.

[4] H. Kwon, G.-G. Lee, S.-G. Kim, B.-W. Lee, W.-C. Seo, M. Leparoux, Materials Science and Engineering: A, 632 (2015) 72-77.

[5] K. Fukuchi, K. Sasaki, K. Katagiri, T. Imanishi, A. Kakitsuji, Procedia Engineering, 10 (2011) 912-917.

[6] A. Shadravan, Z. Sadeghian, A. Nemati, S. Mohammadi, Surface and Coatings Technology, 275 (2015) 224-231.

[7] S.A. Hosseini, K. Ranjbar, R. Dehmolaei, A.R. Amirani, Journal of Alloys and Compounds, 622 (2015) 725-733.

[8] Y.-J. Yim, S.-J. Park, Journal of Industrial and Engineering Chemistry, 21 (2015) 155-157.

[9] Y. Tong, M. Zhang, P. Xia, L. Wang, J. Zheng, W. Li, J. Xu, Journal of Magnetism and Magnetic Materials, 406 (2016) 35-41.

[10] F. Yu, J. Ma, J. Wang, M. Zhang, J. Zheng, Chemosphere, 146 (2016) 162-172. 
[11] J.G. Park, D.H. Keum, Y.H. Lee, Carbon, 95 (2015) 690-698.

[12] B. Chen, S. Li, H. Imai, L. Jia, J. Umeda, M. Takahashi, K. Kondoh, Composites Science and Technology, 113 (2015) 1-8.

[13] S. Dong, J. Zhou, H. Liu, Y. Wu, D. Qi, Mechanics of Materials, 91, Part 1 (2015) 1-11.

[14] X. Long, Y. Bai, M. Algarni, Y. Choi, Q. Chen, Materials Science and Engineering: A, 645 (2015) 347-356.

[15] H.R. Ezatpour, A. Chaichi, S.A. Sajjadi, Materials \& Design, 88 (2015) 1049-1056.

[16] Y.-1. Kang, Q.-h. Han, X.-m. Zhao, M.-h. Cai, Materials \& Design, 44 (2013) 331-339.

[17] D. Jeyasimman, R. Narayanasamy, R. Ponalagusamy, V. Anandakrishnan, M. Kamaraj, Materials \& Design, 64 (2014) 783-793.

[18] S. Ni, Y.B. Wang, X.Z. Liao, S.N. Alhajeri, H.Q. Li, Y.H. Zhao, E.J. Lavernia, S.P. Ringer, T.G. Langdon, Y.T. Zhu, Materials Science and Engineering: A, 528 (2011) 33983403.

[19] R.I. Babicheva, S.V. Dmitriev, Y. Zhang, S.W. Kok, N. Srikanth, B. Liu, K. Zhou, Computational Materials Science, 98 (2015) 410-416.

[20] J. Jian, J.H. Lee, Y. Liu, F. Khatkhatay, K. Yu, Q. Su, X. Zhang, L. Jiao, H. Wang, Materials Science and Engineering: A, 650 (2016) 445-453.

[21] Y. Chen, T. Liu, C. Chen, W. Guo, R. Sun, S. Lv, M. Saito, S. Tsukimoto, Z. Wang, Ceramics International, 39 (2013) 6607-6610.

[22] M. G, S. A, S.J. G.A, K. S, Journal of Molecular Catalysis A: Chemical, 411 (2016) 167178.

[23] M. Tokur, H. Algul, M. Uysal, T. Cetinkaya, A. Alp, H. Akbulut, Surface and Coatings Technology, 288 (2016) 62-68.

[24] E.T. Thostenson, Z. Ren, T.-W. Chou, Composites science and technology, 61 (2001) 1899-1912.

[25] T. Kuzumaki, K. Miyazawa, H. Ichinose, K. Ito, Journal of Materials Research, 13 (1998) 2445-2449.

[26] J. Carpenter, T. Nizolek, R. McCabe, M. Knezevic, S. Zheng, B. Eftink, J. Scott, S. Vogel, T. Pollock, N. Mara, Acta Materialia, 92 (2015) 97-108.

[27] P. Juř́ik, P. Slepička, Z. Kolská, V. Švorčík, Materials Letters, 165 (2016) 33-36.

[28] A.R. Shojaei, A. Vaez, Z. Nourbakhsh, Z.S. Madaniyan, Thin Solid Films, 556 (2014) 425-433.

[29] E.M. Jackson, P.E. Laibinis, W.E. Collins, A. Ueda, C.D. Wingard, B. Penn, Composites Part B: Engineering, 89 (2016) 362-373. 
[30] J.-H. Lin, Z.-I. Lin, Y.-J. Pan, C.-L. Huang, C.-K. Chen, C.-W. Lou, Composites Part B: Engineering.

[31] L. Longbiao, Materials Science and Engineering: A, 648 (2015) 235-242.

[32] T. Gao, Y. Zhao, G. Zhou, Y. Han, Y. Zheng, Z. Shan, D. Hui, F. Xu, Y. Qiu, Composites Part B: Engineering, 77 (2015) 122-128.

[33] T. Clyne, P. Withers, An introduction to metal matrix composites, Cambridge University Press, 1995.

[34] M. Djafri, M. Bouchetara, C. Busch, S. Weber, Wear, 321 (2014) 8-15.

[35] M. Pevec, G. Oder, I. Potrč, M. Šraml, Engineering Failure Analysis, 42 (2014) 221-230.

[36] S.A. Mutasher, Materials \& Design, 30 (2009) 215-220.

[37] O. Montagnier, C. Hochard, Materials \& Design, 46 (2013) 88-100.

[38] A. Muthuraja, S. Senthilvelan, International Journal of Refractory Metals and Hard Materials, 51 (2015) 91-101.

[39] N.A. Özbek, A. Çiçek, M. Gülesin, O. Özbek, Tribology International, 94 (2016) 223233.

[40] J.E. Spowart, T.W. Clyne, Acta Materialia, 47 (1999) 671-687.

[41] J.M. Kunze, H.N.G. Wadley, Materials Science and Engineering: A, 244 (1998) 138-144.

[42] R.A. Shatwell, Materials Science and Engineering: A, 259 (1999) 162-170.

[43] M.J. Treacy, T. Ebbesen, J. Gibson, (1996).

[44] E.W. Wong, P.E. Sheehan, C.M. Lieber, Science, 277 (1997) 1971-1975.

[45] A. Esawi, K. Morsi, Composites Part A: Applied Science and Manufacturing, 38 (2007) 646-650.

[46] E.T. Thostenson, C. Li, T.-W. Chou, Composites Science and Technology, 65 (2005) 491516.

[47] T. Noguchi, A. Magario, S. Fukazawa, S. Shimizu, J. Beppu, M. Seki, Materials Transactions, 45 (2004) 602-604.

[48] S.I. Cha, K.T. Kim, S.N. Arshad, C.B. Mo, S.H. Hong, Advanced Materials, 17 (2005) $1377-1381$.

[49] X. Hu, T. Wang, X. Qu, S. Dong, The Journal of Physical Chemistry B, 110 (2006) 853857.

[50] S.R. Dong, J.P. Tu, X.B. Zhang, Materials Science and Engineering: A, 313 (2001) 8387.

[51] T. Laha, A. Agarwal, T. McKechnie, S. Seal, Materials Science and Engineering: A, 381 (2004) 249-258. 
[52] Y. Tang, H. Cong, R. Zhong, H.-M. Cheng, Carbon, 42 (2004) 3260-3262.

[53] M.R. Akbarpour, M. Farvizi, D.J. Lee, H. Rezaei, H.S. Kim, Materials Science and Engineering: A, 638 (2015) 289-295.

[54] P. Quang, Y.G. Jeong, S.C. Yoon, S.H. Hong, H.S. Kim, Journal of Materials Processing Technology, 187-188 (2007) 318-320.

[55] S. Bakshi, D. Lahiri, A. Agarwal, International Materials Reviews, 55 (2010) 41-64.

[56] T. Kuzumaki, O. Ujiie, H. Ichinose, K. Ito, Advanced Engineering Materials, 2 (2000) 416-418.

[57] R. Zhong, H. Cong, P. Hou, Carbon, 41 (2003) 848-851.

[58] M. Tan, X. Zhang, Materials Science and Engineering: A, 244 (1998) 80-85.

[59] I. Sabirov, O. Kolednik, R. Valiev, R. Pippan, Acta materialia, 53 (2005) 4919-4930.

[60] M. Alizadeh, M. Paydar, D. Terada, N. Tsuji, Materials Science and Engineering: A, 540 (2012) 13-23.

[61] M. Ardeljan, M. Knezevic, T. Nizolek, I. Beyerlein, S. Zheng, J. Carpenter, R. McCabe, N. Mara, T. Pollock, IOP Conference Series: Materials Science and Engineering, IOP Publishing, 2014, pp. 012170.

[62] M. Knezevic, T. Nizolek, M. Ardeljan, I.J. Beyerlein, N.A. Mara, T.M. Pollock, International Journal of Plasticity, 57 (2014) 16-28.

[63] I. Sabirov, O. Kolednik, R. Pippan, Metallurgical and Materials Transactions A, 36 (2005) 2861-2870.

[64] Y. Xue, B. Jiang, L. Bourgeois, P. Dai, M. Mitome, C. Zhang, M. Yamaguchi, A. Matveev, C. Tang, Y. Bando, Materials \& Design, 88 (2015) 451-460.

[65] M. Jahedi, M.H. Paydar, Materials Science and Engineering: A, 527 (2010) 5273-5279.

[66] M.H. Paydar, M. Reihanian, E. Bagherpour, M. Sharifzadeh, M. Zarinejad, T.A. Dean, Materials Letters, 62 (2008) 3266-3268.

[67] R. Lapovok, D. Tomus, B. Muddle, Materials Science and Engineering: A, 490 (2008) 171-180.

[68] R.Y. Lapovok, Journal of Materials Science, 40 (2005) 341-346.

[69] M. Jahedi, M.H. Paydar, M. Knezevic, Materials Characterization, 104 (2015) 92-100.

[70] M. Jahedi, M. Knezevic, M.H. Paydar, Journal of Materials Engineering and Performance, 24 (2015) 1471-1482.

[71] M. Jahedi, M.H. Paydar, S. Zheng, I.J. Beyerlein, M. Knezevic, Materials Science and Engineering: A, 611 (2014) 29-36.

[72] X. Sun, W. Zhao, Materials Science and Engineering: A, 390 (2005) 366-371. 
[73] M.B. Nardelli, B.I. Yakobson, J. Bernholc, Physical review letters, 81 (1998) 4656.

[74] Y. Iwahashi, Z. Horita, M. Nemoto, T.G. Langdon, Acta Materialia, 45 (1997) 4733-4741.

[75] Y. Iwahashi, Z. Horita, M. Nemoto, T.G. Langdon, Acta Materialia, 46 (1998) 3317-3331.

[76] M. Nemoto, Z. Horita, M. Furukawa, T.G. Langdon, Materials science forum, Trans Tech Publ, 1999, pp. 59-66.

[77] V.V. Stolyarov, Y.T. Zhu, I.V. Alexandrov, T.C. Lowe, R.Z. Valiev, Materials Science and Engineering: A, 299 (2001) 59-67.

[78] M. Furukawa, Z. Horita, M. Nemoto, T.G. Langdon, Journal of Materials Science, 36 2835-2843.

[79] Y. Iwahashi, J. Wang, Z. Horita, M. Nemoto, T.G. Langdon, Scripta Materialia, 35 (1996) 143-146.

[80] V.M. Segal, Materials Science and Engineering: A, 197 (1995) 157-164.

[81] K. Hibbitt, I. Sorensen, Pawtucket, RI, USA: Hibbitt Karlsson and Sorensen Inc, (2003).

[82] B. Mani, M. Jahedi, M.H. Paydar, Materials Science and Engineering: A, 528 (2011) 4159-4165.

[83] B. Mani, M. Jahedi, M.H. Paydar, Powder Technology, 219 (2012) 1-8.

[84] M. Paydar, M. Reihanian, E. Bagherpour, M. Sharifzadeh, M. Zarinejad, T. Dean, Materials \& Design, 30 (2009) 429-432.

[85] F. Lange, L. Atteraas, F. Zok, J. Porter, Acta metallurgica et materialia, 39 (1991) 209219.

[86] Z. Wang, T.-K. Chen, D. Lloyd, Metallurgical Transactions A, 24 (1993) 197-207.

[87] V. Stolyarov, R. Lapovok, I. Brodova, P. Thomson, Materials Science and Engineering: A, 357 (2003) 159-167.

[88] D. Tabor, Proceedings of the Royal Society of London A: Mathematical, Physical and Engineering Sciences, The Royal Society, 1948, pp. 247-274.

[89] S. Simões, F. Viana, M.A.L. Reis, M.F. Vieira, Composite Structures, 126 (2015) 114122.

[90] G.L. Hwang, Y.T. Shieh, K.C. Hwang, Advanced Functional Materials, 14 (2004) 487491.

[91] K. Oh-Ishi, Z. Horita, M. Nemoto, M. Furukawa, T.G. Langdon, Metallurgical and Materials Transactions A, 29 (1998) 2011-2013.

[92] H. Pal, A. Chanda, M. De, Journal of alloys and compounds, 278 (1998) 209-215.

[93] M.A. Meyers, A. Mishra, D.J. Benson, Progress in materials science, 51 (2006) 427-556.

[94] J.C. Li, Mechanical properties of nanocrystalline materials, CRC Press, 2011. 
[95] P. Prangnell, S. Barnes, S. Roberts, P. Withers, Materials Science and Engineering: A, 220 (1996) 41-56.

[96] M. Jahedi, B. Mani, S. Shakoorian, E. Pourkhorshid, M. Hossein Paydar, Materials Science and Engineering: A, 556 (2012) 23-30.

[97] M.A. Meyers, K.K. Chawla, Mechanical behavior of materials, Cambridge university press Cambridge, 2009.

[98] C. Li, X. Wang, W. Liu, K. Wu, H. Shi, C. Ding, X. Hu, M. Zheng, Materials Science and Engineering: A, 597 (2014) 264-269.

[99] T. Sakai, H. Miura, A. Goloborodko, O. Sitdikov, Acta Materialia, 57 (2009) 153-162.

[100] T. Sakai, A. Belyakov, R. Kaibyshev, H. Miura, J.J. Jonas, Progress in Materials Science, 60 (2014) 130-207.

[101] M. Bacca, D.R. Hayhurst, R.M. McMeeking, Mechanics of Materials, 90 (2015) 148156.

[102] M. Jahedi, M.H. Paydar, Materials Science and Engineering: A, 528 (2011) 8742-8749.

[103] N. Pardis, R. Ebrahimi, Materials Science and Engineering: A, 527 (2009) 355-360.

[104] N. Pardis, B. Talebanpour, R. Ebrahimi, S. Zomorodian, Materials Science and Engineering: A, 528 (2011) 7537-7540.

[105] S. Semiatin, D. Delo, E. Shell, Acta Materialia, 48 (2000) 1841-1851.

[106] J.-Y. Suh, H.-S. Kim, J.-W. Park, J.-Y. Chang, Scripta materialia, 44 (2001) 677-681.

[107] K. Nakashima, Z. Horita, M. Nemoto, T.G. Langdon, Materials Science and Engineering: A, 281 (2000) 82-87.

[108] W. Xu, X. Wu, T. Honma, S. Ringer, K. Xia, Acta Materialia, 57 (2009) 4321-4330.

[109] E. El-Danaf, M. Soliman, A. Almajid, M. El-Rayes, Materials Science and Engineering: A, 458 (2007) 226-234.

[110] G. Ramu, R. Bauri, Materials \& Design, 30 (2009) 3554-3559.

[111] M.S. Arab, N. El Mahallawy, F. Shehata, M.A. Agwa, Materials \& Design, 64 (2014) 280-286.

[112] M. Saravanan, R.M. Pillai, K.R. Ravi, B.C. Pai, M. Brahmakumar, Composites Science and Technology, 67 (2007) 1275-1279. 